\title{
A ORGANIZAÇÃO TEMÁTICA DA SENTENÇA DA JURISPRUDÊNCIA COMO MECANISMO DE CONSTRUÇÃO DA IDENTIDADE SOCI- AL/PROFISSIONAL DO JUIZ DO STF
}

\author{
Valeria lensen Bortoluzzi
}

\section{RESUMO}

O presente trabalho tem como objetivo apresentar uma análise da metafunção textual (Halliday e Matthiessen, 2004) de um texto de jurisprudência, discutindo como a escolha dos elementos que servirão como tema da oração contribui para a construção da identidade social/profissional de um juiz do Supremo Tribunal Federal, (de acordo com Fairclough, 2001). Os resultados demonstram uma preferência pelo uso de temas marcados, acarretando em apagamento do sujeito (ou colocação do mesmo em segundo plano). Tal atitude revela a construção da identidade do juiz como um ser que se confunde com o Direito, como se ambos formassem um só ser.

\section{INTRODUÇÃO}

Durante muito tempo, houve uma tradição de se analisar o discurso jurídico pelo viés da retórica, da lógica argumentativa, tanto que teóricos da argumentação baseiamse na análise de textos jurídicos para exemplificar/embasar suas discussões sobre 0 assunto (Perelman e Olbrechts-Tyteca, 1996; Alexy, 2001, por exemplo). Tais teorias tomam por base os estudos de Aristóteles e os atualizam, mas continuam a teorizar sobre acordos, fatos, verdades, pressuposições, valores, hierarquias e lugares, muito mais embasados em estudos filosóficos que em estudos lingüísticos. Quando buscam, na lingüística, elementos para embasar seus estudos, concentram o foco em mecanismos lingüísticos da argumentação muito específicos, quais sejam: os operadores argumentativos e os verbos modalizadores "dever" e "poder" (Petri, 1994, por exemplo).

Apesar da validade inquestionável de tais estudos, eles não foram capazes de explicitar como a linguagem se organiza para produzir os efeitos de sentido necessários ao entendimento do leitor de textos jurídicos. Isso porque as teorias da argumentação estão mais preocupadas em tentar explicitar como o orador deve usar seus argumentos para persuadir seu auditório, como se a argumentação existisse sem a linguagem, e não fosse constituída por ela; como se 0 orador existisse sem 0 auditório, e não fosse constituído por ele. Talvez isso explique porque o texto jurídico é tão inacessível ao leitor leigo, e muitas vezes, até ao leitor especializado. Se não há muita preocupação em interagir com o leitor, o texto não precisa ser legível.

Fairclough $(2001 ; 2003)$ afirma, repetidas vezes, que os textos estão revestidos de discursos vários que constituem o ethos daqueles que os produzem. Sendo assim, é possível generalizar a afirmação de que se o texto é inacessível, aquele que o produz também é. O presente trabalho, então, tem por objetivo mostrar como os juízes das instâncias superiores constroem suas identidades sociais/profissionais nos textos que produzem, via análise da sentença como mensagem, conforme apresentado 
na Gramática Sistêmico-Funcional (GSF) (Halliday e Matthiessen, 2004), e corroborado por Martin (1997), Hasan e Fries (1995), Eggins (1994), Leila Bárbara e Gouveia $(2003,2001)$.

De acordo com Halliday e Matthiessen (2004: 64) o que caracteriza uma sentença como mensagem é sua estrutura temática, que está dividida em TEMA e REMA. Neste texto vou me dedicar a discutir a estrutura temática da jurisprudência, a partir da análise de 11 jurisprudências de habeas corpus do Supremo Tribunal Federal, sendo uma jurisprudência para cada um dos 11 membros do Supremo. Neste texto os resultados apresentados fazem referência à grande maioria das jurisprudências.

\section{A QUESTÃO DO TEMA NA GSF}

De acordo com Halliday e Matthiessen (2004:64), o TEMA de uma sentença, em Inglês, é indicado por estar colocado em primeiro lugar na sentença, servir de ponto de partida para a mensagem e ter alguma função na estrutura experencial da mesma, sendo que todo o resto que vai do verbo em diante é chamado de REMA. Essa visão é corroborada por Hassan e Fries (1995: xxvi), Eggins (1994: 275) e Martin (1997:21). Esse último ainda afirma que o sistema do TEMA organiza a sentença para mostrar o seu contexto local em relação ao contexto geral do texto ${ }^{1}$.

O TEMA típico, em Inglês, é o sujeito, pois a estrutura padrão da sentença inglesa é SVO. Quando o TEMA é típico, segundo a GSF, ele é não-marcado. A GSF distingue os temas como marcado ou não-marcado para dar conta das estruturas da língua que não seguem o padrão. Na língua inglesa é bastante simples fazer esta distinção, pois o inglês sempre possui um elemento nominal que funcione como sujeito da sentença. Então, em inglês, todo o elemento que funcionar como sujeito da sentença e estiver na posição do sujeito na estrutura padrão, seja ele um pronome, um substantivo, uma locução substantiva ou uma oração substantiva, ou um pronome expletivo, será considerado TEMA não-marcado. Todos os outros elementos que vierem colocados na posição do sujeito e que não tiverem função semântica de sujeito, serão considerados temas marcados.

No entanto, a transposição da teoria do TEMA da GSF para a língua portuguesa não é tão simples, pois apesar da estrutura sintática padrão do português ser a mesma do inglês (SVO), o português é uma língua pro-drop, ou seja, que nem sempre apresenta um elemento nominal funcionando como sujeito da sentença. Gouveia e Bárbara $^{2}$ (2001: 5-6) afirmam que para línguas como o português, as conseqüências de ser uma língua pro-drop são muitas: de um lado, não existe sujeito expletivo; de outro, existe a possibilidade de termos sujeitos pós-verbais; e, ainda, a característica de ser pro-drop está associada com uma rica morfologia verbal em termos de desi-

\footnotetext{
1 "The system of THEME organizes de clause to show what its local context is in relation to the general context of the text it serves in;"(...) (Martin, 1997:21)

2 "For languages such as Portuguese, the consequences or correlations of being a pro-drop language are several: on the one hand, there are no expletive Subjects in standard Portuguese as there are in English or French (...); on the other hand, there is the possibility of having post-verbal Subjects (...). Lastly, the pro-drop characteristic seems to be connected with a rich verbal morphology in terms of person and number, although the opposite of this may not be true." (Gouveia e Barbara, 2001:5-6)
} 
nências número-pessoais, fazendo com que a utilização de sujeitos, em situações discursivas várias, seja redundante.

O fato de o português apresentar particularidades lingüísticas que o diferem do inglês, língua sobre a qual foi elaborada a GSF, nos leva ao problema de identificação do TEMA nos períodos. Se considerarmos que: a) o TEMA localiza-se na posição inicial da sentença; b) quando for típico é considerado não-marcado; e c) a estrutura padrão da sentença em português é SVO, então, chegamos à conclusão que 0 TEMA não-marcado em português é o sujeito, certo? Não é bem assim.

Em primeiro lugar, nem sempre o sujeito é pronunciado ${ }^{3}$, pois existe uma marca do sujeito no verbo, que é a desinência de número-pessoa. A ausência de um sujeito pronunciado em português é muito freqüente, pois a sua pronúncia, na maioria dos casos, é considerada redundante. Isso só não ocorre com a $3^{\underline{a}}$ pessoa do singular, que geralmente precisa ser nomeada. Nesse caso, a tipicidade ficaria por conta da ausência do sujeito e utilização do verbo como ponto de partida da mensagem. Então, poderíamos considerar o verbo como TEMA não-marcado? De acordo com Gouveia e Bárbara (2001:14), tanto o sujeito quanto o verbo podem ser TEMAS nãomarcados, embora mesmo em português a escolha natural para o TEMA seja o sujeito. O verbo como TEMA não-marcado ocorreria, segundo os autores, nos períodos com verbos impessoais, como os utilizados para expressar processos meteorológicos, verbo haver com sentido de existir e certas ocorrências dos verbos fazer e ser. Nessas situações é natural não haver sujeito dos períodos. Outro caso de verbo em posição temática e não-marcado é o do imperativo, em que a ocorrência de um sujeito é incomum e só ocorre por razões enfáticas.

Em segundo lugar, é muito comum a ocorrência, em português, da estrutura VSO, ou seja, o sujeito posposto ao verbo. Nesse caso, Gouveia e Bárbara (2001:15) assumem a postura que o verbo seria um TEMA marcado. Outras ocorrências de verbos em posição de TEMA marcado são os períodos em voz passiva, os verbos reflexivos e elipses de sujeito em razão da coesão textual.

O levantamento teórico realizado até aqui teve por objetivo apresentar alguns aspectos da questão do TEMA para a GSF. Tal levantamento é apenas uma pequena amostra da teorização existente e deve ser amplamente expandida com a leitura dos textos citados. No entanto, esse levantamento nos permite abordar mais detalhadamente a questão do ethos (identidade social) do juiz no texto da jurisprudência. Através da análise da estrutura temática dos períodos da jurisprudência, podemos perceber que posição é ocupada pelos juízes nesse evento sócio-discursivo e como essa posição é ocupada.

\section{O TEMA E A CONSTRUÇÃO DAS IDENTIDADES SOCIAIS / PROFISSIONAIS DOS JUÍZES DE INSTÂNCIAS SUPERIORES}

De acordo com Fairclough (2001), uma análise do discurso só pode ser conduzida via análise lingüística do texto. Nas palavras do autor (Fairclough, 2001: 90), "a língua varia de acordo com a natureza da relação entre os participantes em interações, o tipo de evento social, os propósitos sociais das pessoas na interação, e assim pr

\footnotetext{
${ }^{3}$ A noção de sujeito pronunciado, utilizada neste artigo, foi importada da Gramática Gerativa, em que sujeito pronunciado é aquele que está explícito, tanto na fala quanto na escrita. Outras informações podem ser obtidas em Miotto, Silva e Lopes, 2004.
} 
diante (Downes, 1984)." Portanto, não se pode analisar discurso - e a construção de identidades sociais/profissionais é parte dessa análise - sem analisar a linguagem.

Para o autor, analisar criticamente discurso ${ }^{4}$ é compreender que o mesmo "contribui para a constituição de todas as dimensões da estrutura social que, direta ou indiretamente, o [indivíduo] moldam e o restringem: suas próprias normas e convenções, como também relações, identidades e instituições que lhe são subjacentes. $O$ discurso é uma prática, não apenas de representação do mundo, mas de significação do mundo, (...)." (Fairclough, 2001:91). Assim, o discurso possui efeitos construtivos que são: construção das identidades sociais (posições de sujeito ${ }^{5}$ e tipos de "eu"); construção das relações sociais; e construção de sistema de conhecimento e crença (Idem: ibidem). Neste trabalho, me proponho a analisar como a estrutura temática do texto da jurisprudência contribui para que entendamos como os juizes constroem seus ethos nesse evento discursivo. O ethos, para Fairclough, é "o comportamento total de um(a) participante, do qual seu estilo verbal (falado e escrito) e tom de voz fazem parte, expressa o tipo de pessoa que ele(a) é e sinaliza sua identidade social, bem como sua subjetividade" (2001:181-2), é parte de um processo mais amplo de 'modelagem', constituído pelos comportamentos verbais e não-verbais de todos os que participam do evento, num determinado contexto sócio-histórico (2001:207). Significa dizer que o juiz constrói seu ethos na interação com todo um sistema, cujo estudo é amplo demais para caber neste pequeno trabalho. Por conta disso, trabaIhei apenas com as escolhas lexicais colocadas na posição temática dos períodos.

\subsection{Algumas características lingüísticas do texto da jurisprudência}

Jurisprudência é entendida aqui como o conjunto de decisões uniformes e constantes dos tribunais, resultantes da aplicação de normas a casos semelhantes, constituindo uma norma geral aplicável a todas as hipóteses similares ou idênticas. É o conjunto de normas emanadas dos juízes em sua atividade jurisdicional (Diniz, 2001, p. 290). Comumente, o termo "jurisprudência" é utilizado para fazer referência às decisões emanadas dos tribunais superiores, conforme Petri (1994), e é nesse sentido que a jurisprudência foi analisada aqui.

Uma análise prévia da configuração contextual e da estrutura potencial de gênero da jurisprudência ${ }^{6}$ revelou que esse é um gênero discursivo muito estável, estando de acordo com a prática discursiva da qual emana, que é altamente ritualizada. Segundo Bourdieu (1996: 89), a ritualização é uma das formas de manutenção dos universos simbólicos, que se manifestará nos discursos ritualizados. As jurisprudências analisadas aqui são excelentes exemplos de discursos rituais. $O$ texto de jurisprudência, que pode ser acessado, na forma escrita, por qualquer cidadão, é um texto produzido para ser lido pelo relator aos seus pares, em uma sessão fechada, na qual não é permitida a presença de pessoas não autorizadas previamente, o que acontece muito raramente. O relator é, nas palavras de Bourdieu (idem: ibidem), o porta-voz desse universo simbólico, "que consegue agir com palavras em relação a outros agentes e, por meio de seu trabalho, agir sobre as próprias coisas, na medida em que sua fala concentra o capital simbólico acumulado pelo grupo que the conferiu o mandato e do qual é, por assim dizer, o procurador."

\footnotetext{
${ }^{4} \mathrm{Na}$ concepção de Fairclough (2001:90), e na minha também, discurso é concebido como uma forma de prática social.

${ }^{5}$ Sujeito aqui não é a função sintática, mas sinônimo de indivíduo (função semântica).

${ }^{6}$ Trabalho apresentado em pôster no VII Encontro Nacional de Interação em Linguagem Verbal e Não-Verbal e I Simpósio Internacional de Análise de Discurso Crítica.
} 
Nas sessões, não são permitidas filmagens da imprensa e todas as informações que chegam à mídia são controladas. Por isso, não se pôde fazer, até o momento, caracterização mais apurada das condições de produção da jurisprudência.

As condições de distribuição do texto já são mais fáceis de se apurar, pois, como todo o texto oficial, precisa ser publicado em órgão de imprensa oficial (DJU e DJE). Ao serem publicadas nos diários oficiais, as jurisprudências são facilmente acessadas por juristas de toda ordem (advogados, juízes, promotores, procuradores, delegados, etc.). Existem, também, revistas especializadas em Direito que compilam jurisprudências. Dessa forma, alunos de Direito têm acesso aos textos, também.

Ao determinarmos as condições de distribuição da jurisprudência, determinamos, também, parte das condições de consumo do texto. Já sabemos quem consome o texto, agora é preciso determinar por que consome. Os juristas usam a jurisprudência com alta freqüência, pois ela serve para embasar a argumentação em torno de um fato jurídico. Desde os primeiros semestres do curso de Direito, os alunos são orientados a pesquisar jurisprudência para embasar seus estudos. A jurisprudência é considerada uma das fontes do direito, sendo, então, sua leitura indispensável para a tomada de novas decisões.

Todas essas condições estão reveladas no texto, através de escolhas lingüísticas que marcam e caracterizam o gênero. Algumas das características lingüísticas recorrentes no gênero são:

a) uso dos tempos presente e passado para a apresentação do relatório dos autos e das decisões anteriores, em estrutura de subordinação, sendo que há predominância no uso das orações subordinadas completivas;

b) uso de estrutura de passiva (no início do texto), passando para a voz ativa no modo indicativo, em estruturas declarativas, mantendo-se assim ao longo do texto;

c) modalização basicamente operada pelo uso de verbos causativos ${ }^{7}$ (no relato dos fatos) e processos mentais (como o uso predominante dos verbos acordar (entrar em acordo), negar e/ou dar provimento, decidir), demonstrando que as decisões são finais e não cabem ser criticadas ou recusadas;

d) uso de verbos de possibilidade deôntica e epistêmica, e de advérbios asseverativos, sendo mais comuns na parte final do texto (denominada ou não de voto), pois é nesse instante que é estabelecido o que deve ou não ser feito e quem tem competência para tal;

e) predominância de TEMAS marcados, demonstrando uma tendência à posposição ou apagamento do sujeito.

\subsection{A linguagem como meio de representação de identidades sociais}

Foi o item (e) que me chamou a atenção quando da leitura dos 11 exemplares. A maior parte dos períodos, que são muito complexos, encadeando, por vezes, 4 ora-

\footnotetext{
${ }^{7}$ Classificação segundo a Gramática de Usos do Português
} 
ções, começa por circunstancializadores, verbos ou está na voz passiva, sem agente. Não vou fazer uma análise da oração, e sim, do período.

Nas 11 jurisprudências analisadas verifiquei que:

1) há 221 períodos, excetuando-se as citações diretas;

2) dos 221 períodos apenas 53 possuem temas não-marcados, ocupados por sujeitos (36) ou objetos como sujeitos da passiva (17) (exemplo 1);

\section{Exemplo 1:}

A douta Procuradoria-Geral da República opinou pelo indeferimento da ordem, invocando o já referido enunciado. (HC 84553-3)

A decisão de primeiro grau que decretou a prisão preventiva dos denunciados foi proferida após a cassação do mandato do ora paciente. (HC 84875-3)

3) dos 221 períodos, 80 possuem verbo como TEMA marcado, 17 são verbos em 1aㅡ pessoa e 63 são verbos em outras pessoas (exemplo 2);

\section{Exemplo 2:}

Dispensei as informações ao vislumbrar elementos suficientes ao exame da causa. (HC 84776-5)

Afirma que a instrução do processo já terminou, devendo, pois, ser afastado o primeiro fundamento da decisão que determinou a prisão preventiva, qual seja, de garantia da instrução criminal. (HC 84474-0)

4) dos 221 períodos, 34 possuem sujeito posposto ao verbo (exemplo 3);

\section{Exemplo 3:}

Sustenta o impetrante que a sentença condenatória é nula. (HC 84.590-8)

Contra essa decisão se insurge o impetrante por meio do presente HABEAS. (HC 83.955-0) 
5) dos 221 períodos, em 51 deles o sujeito foi apagado ou não foi pronunciado (exemplo 4);

\section{Exemplo 4:}

Registre-se, ademais, que a jurisprudência da Corte já assentou o entendimento de que, nos Tribunais, a interrupção da prescrição ocorre na data da sessão que recebe a denúncia, e não no momento de publicação do respectivo acórdão. (HC 84606-8)

Em conseqüência, requer o trancamento da ação penal em que o paciente figura como réu. (HC 84238-1)

6) em 66 períodos, dos 221, o TEMA é um termo circunstancializador ou um conetivo (exemplo 5);

Exemplo 5:

Embora não escolha os fundamentos da impetração, tais como deduzidos pelo ora impetrante, consideradas as razões precedentemente expostas em meu voto, não posso ignorar a situação dramática em que se acha o ora paciente. (HC 83657-7)

$\underset{\text { writ. (HC 84728-5) }}{\frac{\text { Nesses termos, }}{\text { it. }} \text { meu voto é pelo indeferimento do }}$

7) em apenas 17 ocorrências o verbo está na 1a pessoa do singular (exemplo 6);

Exemplo 6:

Esse o quadro, julgo prejudicado o hábeas corpus: é o meu voto. (HC 84474-0)

Tenho para mim que todos os elementos ora referidos justificam o acolhimento, em parte, da postulação deduzida pelo ilustre impetrante, (...). (HC 83657-7) 
Os dados apresentados acima nos mostram a predominância do TEMA marcado no texto da jurisprudência e que os sujeitos dos períodos são colocados em posição secundária, visto que em 85 períodos o sujeito ou foi apagado, ou foi posposto ao verbo, ou, ainda, foi elipsado, para ser retomado pelo contexto. Isso demonstra que não há preocupação com o estabelecimento do 'eu' como sujeito das ações, nem a de apresentar as partes, mas o que as move a buscar a justiça. Para Fairclough (2003: 138-9), o apagamento das pessoas nos discursos denota representação mais abstrata do evento discursivo do qual emana a jurisprudência.

Num primeiro momento, poderia interpretar esses dados como uma tentativa de apagar (ou distanciar) a identidade do juiz do evento discursivo em si, na busca da imparcialidade que deveria mover a justiça. Essa seria a conclusão mais fácil, já que anos de tradição em produção textual estabeleceram que a imparcialidade se consegue através do apagamento do sujeito/escritor/autor. No entanto, se analisarmos mais profundamente, veremos que o apagamento ${ }^{8}$ do sujeito deve-se ao fato de que os juizes não falam por si mesmos, eles representam uma instituição denominada 'justiça', que os utiliza como instrumentos de aplicação. Então, a palavra que o juiz profere não é a dele, mas a da justiça.

Nesse ponto percebemos um princípio de classificação que, segundo Fairclough (Idem: ibidem), é importante para que possamos analisar as representações abstratas. Temos, de um lado, aqueles que são a própria justiça e, por isso, não precisam ser nomeados, pois a justiça é seu nome comum (os juízes). De outro, temos aqueles que estão subordinados à justiça e que são tão pouco importantes que não precisam ser nomeados (aqueles que recorrem à justiça). De acordo com Pross (1980: 55-6), nas relações de trabalho e de vida social, em geral, o sujeito deixa de ser aquele que cria seu campo de atuação para se tornar uma figura de um campo criado por outro. Suas representações primárias próprias são substituídas por representações coletivas que desordenam o sujeito e o reordenam como anônimo. $O$ anonimato próprio da segunda classe (a dos menos importantes) deve-se ao fato de que eles não são mais vistos como sujeitos por aqueles que detêm o poder de dizer quem pertence a que classe.

A classificação proposta acima se impõe através dos princípios de divisão do mundo social "que, tão logo se impõem ao conjunto de um grupo, estabelecem o sentido e o consenso sobre o sentindo, em particular sobre a identidade e a unidade do grupo, que está na raiz da realidade da unidade e da identidade do grupo." (Bourdieu, 1996:108). Segundo Bourdieu (Idem: ibidem), as classificações se estabelecem quando se estabelece o "monopólio do poder de fazer ver e de fazer crer, de fazer conhecer e de fazer reconhecer, de impor a definição legítima das divisões do mundo social".

Tal conclusão vem corroborar com a afirmação de Fairclough (2003:160) de que a identidade social não pode ser confundida com a identidade pessoal (ou personalidade), pois a identidade social é assumida na interação verbal e não-verbal com todos os que participam de um evento. Então, a identidade do juiz é social, pois ele assume uma forma de ação de acordo com a sua interação nesse evento discursivo chamado justiça. $\mathrm{O}$ 'eu' juiz é diferente do sujeito que 'interpreta' o papel de juiz.

\footnotetext{
80 apagamento aqui será usado não só para referir a ausência de um sujeito identificável, mas também para a colocação do sujeito em segundo plano e suas elipses.
} 
Como indivíduo, ele/ela é um/uma homem/mulher subordinado(a) à justiça. Como juiz, ele/ela é a própria justiça.

\section{CONSIDERAÇÕES FINAIS}

Ao longo do texto, busquei explicar como a questão do TEMA, visto pelo ângulo da Gramática Sistêmico-Funcional, pode ajudar a entendermos melhor como os juízes dos tribunais superiores constroem suas identidades sociais. Para alcançar minha meta, defini TEMA, a partir da GSF, e apresentei algumas das questões que estão sendo discutidas em virtude a migração da GSF do inglês para o português.

Vimos que a identificação do TEMA em português é bastante complicada, pois nossa língua apresenta peculiaridades, como o fato de a língua portuguesa ser uma língua pro-drop, e de não possuirmos expletivo para os verbos impessoais. O maior problema causado por esses fatos é de não podermos definir claramente quando um TEMA é marcado ou não. Essa distinção é importante para a análise do discurso, pois trata-se de definir o que é natural e, portanto, hegemônico, daquilo que não é natural e repleto de intenções discursivas.

Segundo a GSF, o TEMA típico (ou natural) é o sujeito, ou qualquer elemento lingüístico que funcione como tal, em virtude da estrutura sintática padrão da língua (SVO). Qualquer variação nessa estrutura padrão foge ao âmbito da sintaxe e entra nas esferas semântica e pragmática, portanto, na análise do discurso. É o que pudemos ver na análise do TEMA acima. A quase inexistência de sujeitos sintáticos como TEMA dos períodos das jurisprudências estudadas aponta algo mais que a problemática de transferência de teorias lingüísticas. Aponta para o fato de que os sujeitos constroem-se pela linguagem e que suas escolhas apontam para o que eles são e o que não são, para a imagem que eles têm deles mesmos e aquela que eles querem que vejamos.

Portanto, devemos ter em mente que ao realizarmos qualquer análise textual, não devemos esquecer que a linguagem é mais que um sistema de signos, que ela permite enxergarmos além dos limites das palavras e frases. Fairclough (2003:191-4) nos ensina que analisar texto é analisar a) eventos sociais; b) gêneros discursivos; c) diferenças sociais; d) intertextualidade; e) crenças; f) relações gramaticais e semânticas entre frases e períodos; g) tipos e funções de períodos; h) discursos; i) representação de eventos sociais; j) estilos; k) modalidade; e l) avaliação. Se levarmos todos esses doze aspectos em consideração, então podemos afirmar que realizamos análise crítica e lingüística de textos.

\section{BIBLIOGRAFIA}

ALEXY, R. Teoria da argumentação jurídica. São Paulo: Landy, 2001.

BOURDIEU, P. A economia das trocas lingüísticas. São Paulo: EDUSP, 1996.

DINIZ, Maria Helena. Compêndio de Introdução à Ciência do Direito. $14^{\mathrm{a}}$ ed. São Paulo: Saraiva, 2001.

EGGINS, S. An introduction to sistemic functional linguistics. London: Cassel Imprint, 1994.

FAIRCLOUGH, N. Discurso e mudança social. Brasília: EdUNB, 2001. 
FAIRCLOUGH, N. Analysing discourse: textual analysis for social research. London: Routledge, 2003.

GOUVEIA, C. A. M. e L. BARBARA. "Marked or unmarked that is NOT the question, the question is: Where's the theme?". Paper Presented at the 12th Euro-International Systemic Functional Linguistics Workshop. University of Glasgow, 19-22 July 2000. Direct Paper 45. S. Paulo: PUCSP, 2001.

HALLIDAY, M. A. K. e C. MATTHIESSEN. An Introduction to functional grammar. New York: Arnold, 2004.

HASAN, R. e FRIES, P. H. (eds.). On subject and theme: a discourse functional perspective. Amsterdam: John Benjamins Publishing Co. 1995.

MARTIN, J. R., C. M. I. M. MATTHIESSEN e C. PAINTER. Working with functional grammar. New York: Arnold, 1997.

MIOTTO, C., M. C. F. SILVA,e R. E. V. LOPES. Novo manual de sintaxe. Florianópolis, SC: Insular, 2004.

PERELMAN, C. e L. OLBRECHTS-TYTECA. Tratado da argumentação: a nova retórica. São Paulo: Martins Fontes, 1996.

PETRI, M.J.C. Argumentação lingüística e discurso jurídico. São Paulo: Selinunte, 1994.

PROSS, H. Estructura simbólica del poder. Barcelona, ES: Editorial Gustavo Gili, 1980.

JURISPRUDÊNCIAS ANALISADAS

HC 83657-7 - São Paulo

HC 83955-0 - Rio Grande do Sul

HC 84238-1 - Bahia

HC 84470-7 - Minas Gerais

HC 84474-0 - Rio de Janeiro

HC 84553-3 - São Paulo

HC 84590-8 - Rio de Janeiro

HC 84606-8 - São Paulo

HC 84728-5 - São Paulo

HC 84776-5 - Rio Grande do Sul

HC 84875-3 - Paraná 